\section{¿Es de base genética la adicción a la marihuana?}

Las sensaciones agradables o desagradables que experimenta una persona al fumar marihuana están fuertemente condicionadas por su herencia genética, según indica un nuevo estudio patrocinado por el Instituto Nacional sobre el Abuso de Drogas (NIDA) de los Institutos Nacionales de Salud (NIH) de los Estados Unidos de América. El estudio se basó en el análisis de datos sobre más de 8000 pares de gemelos varones del Registro de Gemelos de la Era de Vietnam. De ellos, 352 pares de gemelos idénticos y 255 de gemelos fraternos declararon que habían usado marihuana más de cinco veces. Los doctores Michael Lyons, Ming Tsuang y colegas de la Escuela de Medicina de la Universidad de Harvard compararon las respuestas de los gemelos idénticos y las de los fraternos a una serie de preguntas detalladas y confidenciales sobre cómo se sentían después de fumar marihuana y si habían experimentado alguna de 23 posibles reacciones que iban desde confusión y paranoia (reacciones negativas) hasta sensaciones muy agradables. Como era de esperar, los que tenían sensaciones agradables usaron la marihuana con mayor frecuencia que los demás. Las experiencias descritas por los gemelos idénticos fueron muy similares, pero no así las de los gemelos fraternos. Como es bien sabido, los gemelos idénticos o monocigóticos comparten todos sus genes, mientras que los fraternos solo comparten alrededor de la mitad de los genes.

Los resultados del estudio sugieren que los genes predisponen la fisiología individual de forma que determina las sensaciones que produce la marihuana. Si bien no se identificaron los genes específicos que determinan esas sensaciones, hay razones para creer que son los que intervienen en el sistema de recompensas del cerebro. Por otra parte, de ello podría desprenderse también una hipótesis similar sobre el uso de otras sustancias adictivas, como el alcohol y la cocaína.

También tuvieron un efecto importante ciertos factores ambientales, como la facilidad de conseguir la marihuana, expectativas en cuanto a los efectos de la droga, influencias de amigos y contactos, y otros factores que son diferentes aun en el caso de gemelos idénticos. Se determinó además que el ambiente compartido o familiar antes de los 18 años no tenía influencia detectable en la respuesta a la marihuana. $\mathrm{Si}$ se consideran las influencias genéticas y ambientales en conjunto, los resultados sugieren que, si bien los factores sociales son importantes, las diferencias individuales asociadas con factores genéticos—quizá en el sistema de recompensas del cerebro- influyen en la decisión de continuar o no el uso de marihuana. Es decir, los factores ambientales llevan al individuo a experimentar con la droga, pero la herencia genética determina si continúa usándola o no.

Alan I. Leshner, Director del NIDA, declaró que el haber descifrado el vínculo entre los factores genéticos y las sensaciones de alguien que consume marihuana abre vías importantes para prevenir el abuso e investigar tratamientos. Quizá aun más importante, los resultados arrojan luz sobre el consumo de drogas y la adicción no solo como problemas sociales, sino también como cuestiones de salud afectadas por la situación biológica de cada individuo. (National Institutes of Health, National Institute on Drug Abuse. Genetic basis indicated for abuse of marijuana. Comunicado de prensa del jueves, 10 de abril de 1997.)

\section{Nueva información sobre los anticonceptivos orales y el riesgo de accidentes cerebrovasculares}

La Organización Mundial de la Salud publicó en la revista Lancet del 24 de agosto de 1996 nuevos datos sobre el riesgo de accidentes cerebrovasculares asociados con el consumo de píldoras anticonceptivas. La información proviene de un extenso estudio iniciado en 1986 por el Programa Especial de Investigaciones, Desarrollo y Formación de Investigadores sobre Reproducción Humana (HRP). El estudio, coordinado en la Escuela de Medicina de Londres del University College, se llevó a cabo en 21 centros de 17 países (5 desarrollados y 12 en desarrollo) con la participación de 2198 mujeres que habían sufrido accidentes cerebrovasculares (casos) y 6086 que no tenían la enfermedad (controles).

Según los datos presentados, el uso de la píldora no aumenta el riesgo de hemorragia cerebral en mujeres menores de 35 años. Sin embargo, el estudio muestra un leve aumento del riesgo en usuarias de más de 35 años. En el caso de accidente cerebrovascular isquémico, se observó un pequeño aumento general en las usuarias actuales. Pero este riesgo era menor en las mujeres más jóvenes (menores de 35 años), las que no fumaban y las que no padecían hipertensión. En ambos tipos de accidente cerebrovascular no se vio aumento del riesgo en las mujeres que habían tomado píldoras anteriormente y ya no las usaban. 
Con miras a hacer las píldoras más inocuas, desde los años setenta se ha reducido la cantidad de las dos hormonas (estrógeno y progestógeno) de uso combinado en las píldoras anticonceptivas. Las píldoras nuevas, llamadas "de dosis reducida" para contrastarlas con las antiguas de dosis alta, son las que más comúnmente se emplean en todas partes del mundo. Uno de los objetivos concretos del estudio fue reevaluar la inocuidad de las píldoras de dosis reducida tal como se consumen en los distintos países. En general, se encontró que las píldoras de dosis reducida entrañan un menor riesgo de accidentes cerebrovasculares que las de dosis alta. En Europa, el riesgo adicional de cualquiera de los dos tipos de accidente cerebrovascular mencionados fue de dos casos anuales por cada 100000 habitantes. En las mujeres menores de 35 años, el riesgo adicional era cercano a solamente un caso anual por 200000 usuarias de la píldora anticonceptiva y aun más bajo en las no fumadoras.

Para mayor información sobre este tema comuníquese con O. Meirik, Director del Componente de Investigación de HRP sobre Vigilancia y Evaluación, OMS, Ginebra 27, Suiza; teléfono (41) 22791 3334: fax: (41) 22791 4171, o con N. Poulter, University College London Medical School, London, England; teléfono: (44) 171391 1721; fax: (44) 171 813 0280. (New data on oral contraceptives and the risk of stroke. Entre Nous: The European Family Planning Magazine 1996; 34-35, December:20.)

\section{Escenarios del futuro del VIH-sida}

Con cada año de convivencia con la epidemia de infección por el virus de la inmunodeficiencia humana (VIH) y el sida se operan cambios sociales que exigen reflexionar sobre los posibles escenarios en los que se desarrollará el futuro de la enfermedad, para poder poner en marcha planes de prevención apropiados. Más que proyecciones estadísticas, se trata de comprender las transformaciones cualitativas que afectan al comportamiento de las nuevas generaciones frente a la epidemia. Fernando Conde Gutiérrez, en su reciente editorial de la Revista Española de Salud Pública, contrasta la "enfermedad acontecimiento" de los años ochenta y su fuerte carga simbólica y metafórica con la "enfermedad crónica" actual y su contexto de desigualdad social. Opina que, por lo menos en el caso de España, las prácticas de mayor riesgo relacionadas con sectores sociales periféricos (como la transmisión por jeringas contaminadas) van a pasar a un segundo plano relativo frente a la práctica sexual entre los jóvenes de las clases medias y medias bajas. Ello llevaría al VIH-sida a escenarios sociales y médicos bastante distintos de los conocidos en la actualidad. El síndrome ya ha perdido parte de sus connotaciones morales y ha adquirido matices de enfermedad concentrada en las clases sociales marginadas. En los Estados Unidos el costo del tratamiento de un enfermo de sida hasta su muerte ha evolucionado de US\$ 57000 en 1988 a \$102 000 en 1992. La desigual posibilidad de acceso al sistema de salud margina a los pobres y en varios países las compañías de seguros rehúsan la participación de enfermos de sida o con seropositividad a VIH.

En cuanto al futuro, lo más probable es que, pese a la gran cantidad de información que tienen disponible, las personas de 16 a 29 años adquieran la enfermedad por vía sexual en función de sus nuevos estilos de vida y del consumo de drogas. Esos nuevos estilos se derivan de los valores socioculturales tendentes a la "precariedad" como forma de vida juvenil. Contribuyen a ello la inseguridad laboral, la sensación de no tener futuro y el nuevo uso del alcohol y las drogas centrado ya no en la búsqueda de novedades, sino de relaciones que ofrezcan un contexto de integración personal y colectiva. Cabe pensar que en 10 años predominarán los casos nuevos asociados a prácticas sexuales sin preservativos y serán residuales los debidos al intercambio de jeringas. Con ello se vería una modificación del perfil de las enfermedades que padecen los enfermos de sida, dada la gran variabilidad genética de los retrovirus. Así como en un principio los más afectados eran homosexuales o usuarios de drogas inyectables y las enfermedades más usuales eran el sarcoma de Kaposi y la neumonía por Pneumocystis carinii, y del mismo modo que en el África las manifestaciones son más digestivas y nerviosas que pulmonares y cutáneas, entre los jóvenes de las clases medias y medias bajas las enfermedades pueden presentar otras características. A este respecto cabe pensar en un incremento importante de las enfermedades de transmisión sexual. El conjunto de cambios descrito no es privativo de España; tiene su paralelo en muchos otros países y requiere abordar desde ahora mismo la tarea de formar y educar a las generaciones más jóvenes. (Conde Gutiérrez G. Escenarios de futuro del vih-sida: de la enfermedad "acontecimiento" a la cronicidad difusa, del estigma moral a las zonas más centrales de la vulnerabilidad social [editorial]. Rev Esp Salud Publica 1997; 71:1-7.)

\section{Terapia nutricional para pacientes de osteoporosis}

En los Estados Unidos la osteoporosis es una enfermedad crónica común que se caracteriza por fragilidad de los huesos y que afecta mayormente a mujeres posmenopáusicas. Algunos factores de riesgo de esta dolencia son la presencia de otras enfermedades crónicas, los medicamentos esteroides, la menopausia prematura y el hábito de fumar. Además de representar una pesada carga 
para la economía del país, la osteoporosis disminuye la autonomía y la calidad de vida de los pacientes.

Las personas con osteoporosis que han tenido fracturas de cadera por lo general están desnutridas y necesitan evaluación e intervención urgentes en cuanto a sus necesidades alimentarias. En el centro de investigación sobre la osteoporosis de la Universidad Creighton de Omaha, Nebraska, un equipo integrado por un médico, una enfermera especialista, un fisioterapeuta y un dietista asesora a los pacientes y administra terapia nutricional. En la evaluación del paciente se toman en cuenta su historia clínica y situación socioeconómica y la medición de valores antropométricos y de nutrientes. Son de especial interés el peso por estatura y las concentraciones séricas de calcio, sal, albúmina y 25-hidroxivitamina D, así como el recuento de leucocitos. Cuando estos valores caen por debajo de lo normal, existe el riesgo de complicaciones y aun de muerte en pacientes hospitalizados. La desnutrición es un factor predictor independiente de mortalidad y de bajas tasas de supervivencia un año después de la fractura de cadera.

En el tratamiento de la osteoporosis se ha prestado insuficiente atención a la función de la vitamina D, que facilita el uso del calcio de la dieta para mineralizar los huesos y aminorar la pérdida de ese elemento. De 80 a $90 \%$ de la vitamina D que requiere el cuerpo se obtiene por exposición a la luz solar. También se obtiene del aceite de hígado de bacalao, del pescado graso y de alimentos enriquecidos, como la leche y los cereales. Los pacientes que no salen mucho al sol ni beben leche por intolerancia a la lactosa suelen tener una deficiencia de vitamina $\mathrm{D}$. La administración simultánea de calcio y vitamina $\mathrm{D}$ produce mayor densidad mineral de los huesos y disminuye las fracturas. Se considera que de 600 a 800 IU diarias de vitamina D ofrecen la protección óptima a las mujeres posmenopáusicas. Cuando se estima necesario, esas pacientes pueden beneficiarse también de suplementos de calcio (1500 mg al día si no están tomando estrógeno o $1000 \mathrm{mg}$ al día si lo están tomando). Por otra parte, es importante limitar el consumo de sal, pues aumenta la excreción de calcio por la orina. Las dietas bajas en calcio suelen ser bajas también en proteínas y otros nutrientes. La administración de proteína suplementaria a pacientes recién hospitalizados con fracturas de cadera ha resultado en una recuperación más rápida y en menos morbilidad y mortalidad que de ordinario. (Packard PT, Heaney RP. Medical nutrition therapy for patients with osteoporosis. J Am Diet Assoc 1997;97(4):414-417.)

\section{Nueva tecnología diagnóstica de estados patológicos del cerebro}

En la medicina neurológica no es raro hallar pacientes que manifiesten algún grado de epilepsia a pesar de que se hayan registrado resultados normales con técnicas de diagnóstico tan avanzadas como los electroencefalogramas (EEG) analógicos, rayos $\mathrm{X}$, tomografía computadorizada y resonancia magnética nuclear. Actualmente se ha logrado un avance en la aplicación de EEG que representa un recurso complementario para diagnósticos difíciles. Mediante digitalización analógica simultánea en 19 canales, la señal se convierte en siluetas cefálicas que aparecen en el monitor a todo color. Esta técnica, llamada mapa electroencefalográfico topográfico (MET), permite escudriñar minuciosa y exhaustivamente las ondas y los ritmos clásicos del EEG al igual que el registro completo, de manera que la probabilidad es muy alta de descubrir cualquier estado patológico. El EEG digital se fundamenta en determinar el espectro de cada ritmo y calcular su potencia. La de un ritmo electroencefalográfico se denomina potencia relativa y la de todos los ritmos en conjunto, potencia total. En ambos casos, la transformada rápida de Fourier (FFT, de Fourier's fast transform) constituye el recurso matemático primario. La FFT permite reducir el EEG a sus componentes de frecuencia y al mismo tiempo medir la energía que cada uno contiene. La potencia se calcula como la cuadrática de la amplitud en microvoltios, y el espectro como el cociente de la cuadrática de la amplitud sobre el número de ondas por segundo o Hertz. La certidumbre de los resultados puede verificarse con recursos estadísticos, lo cual aumenta la probabilidad de acertar en un diagnóstico de enfermedad cerebral que genere cambios electroencefalográficos aunque no sean observables a simple vista. Las figuras pueden ampliarse y presentarse en distintas proyecciones. Esto permite ver toda la cabeza en gran detalle topográfico, lo cual con frecuencia sugiere al médico la ampliación de la anamnesis y contribuye así a un mejor diagnóstico. Los MET sin duda ayudan a comprender síntomas y signos que antes pasaban desapercibidos y son un extraordinario recurso de apoyo en el diagnóstico neurológico. (Peñaloza Rojas JH, Peñaloza A. Nueva tecnología diagnóstica de patología cerebral: los METs. Trib Med 1997; 97(3):148-152.)

\section{Métodos de vigilancia de la diabetes mellitus}

Se ha acumulado una gran cantidad de información que señala la factibilidad de aplazar o aun prevenir muchas de las complicaciones que suelen acompañar a la diabetes mellitus. Para lograrlo es primordial normalizar la concentración de glucosa en la sangre. Sin embargo, la determinación del control de la glucemia es difícil, porque no se puede medir de un momento a otro la concentración de glucosa en la sangre de pacientes ambulatorios. Se ha buscado, por lo tanto, alguna forma de determinar una medida sucedánea de la exposición 
glucémica. Esto se ha alcanzado estableciendo la valoración de productos sanguíneos glucosilados, como la hemoglobina $\mathrm{A}_{1 \mathrm{C}}$, la albúmina glucosilada y la fructosamina. Cada uno de estos productos se comporta de acuerdo con sus propias características cinéticas. Hay datos razonablemente persuasivos de que estos productos no reflejan la media simple sino la media ponderada de la concentración previa de glucosa en plasma durante un período que se aproxima a los 100 días en el caso de la hemoglobina $\mathrm{A}_{1 C^{\prime}}, 40$ días en el de la albúmina glucosilada y 30 días en el de la fructosamina.

La medición de la albúmina glucosilada y de la fructosamina ha sido útil en entornos clínicos y experimentales en los cuales es preferible valorar el control glucémico a intervalos cortos. Sin embargo, ninguna de ellas es tan práctica como la medición de la hemoglobina $A_{1 C}$, que tiene varias ventajas importantes para la valoración a largo plazo del control de la glucemia. No es necesario que el paciente ayune y en condiciones ordinarias la recolección es independiente de fluctuaciones originadas por estrés, ejercicio, temperatura o estabilidad química. Debido a que tiene una vida media larga en el plasma, no requiere medirse con frecuencia. Además, hay muchos datos que muestran una correlación entre los niveles de hemoglobina $\mathrm{A}_{1 \mathrm{C}} \mathrm{y}$ las complicaciones diabéticas. A medida que se progrese en la estandarización de esta medida, más nos acercaremos a una prueba de oro para la vigilancia del control glucémico a largo plazo. Es muy probable que, una vez estandarizada, esa medida se convierta en un instrumento importante del diagnóstico de la diabetes.

No obstante las ventajas expuestas, sigue siendo evidente que el monitoreo de la glucosa en la sangre por el propio paciente en su hogar es la forma que les permite a las personas con diabetes tomar decisiones más independientes y responsables sobre su salud. La única manera de evaluar y corregir la hipo o la hiperglucemia es por medición de la glucosa en la sangre con una tira/metro. Esta tecnología ha progresado enormemente y se están llevando a cabo muchos estudios para hacerla aun más fácil de emplear por los pacientes. (Gavin JJ. Methods of monitoring in diabetes mellitus: the current status. West Indian Med J 1997;46(Suppl 1):27.)

\section{La donación de ovocitos como terapia en infertilidad}

Desde 1983, la donación de ovocitos a mujeres sin función ovárica se ha convertido en una práctica común. La demanda creciente de este procedimiento se debe, entre otras razones, a que las mujeres hoy día suelen postergar la edad del matrimonio y del primer embarazo, mientras su fertilidad disminuye con la edad. Las indicaciones médicas para ovodonación son fallo ovárico prematuro o meno- pausia precoz; disgenesia ovárica; ooforectomía quirúrgica; anomalías genéticas transmisibles a la descendencia; y mujeres con función ovárica que, debido a la edad o a factores patológicos, tienen óvulos de mala calidad que no logran ser fertilizados incluso in vitro, o que si lo son no producen embarazos normales. La donante ideal tiene menos de 34 años, ha concebido anteriormente, no tiene enfermedades genéticas ni hereditarias, y se ha sometido a estudio serológico para sífilis, hepatitis B y C y virus de la inmunodeficiencia humana.

Mientras que la receptora recibe tratamiento hormonal para que su endometrio sea receptivo, la donante se somete a hiperestimulación ovárica. También se lleva a cabo una sincronización de ciclos entre donante y receptora para lograr el momento óptimo de transferencia del embrión. Las tasas de embarazos con donación de ovocitos son más altas que las obtenidas por fertilización in vitro y alcanzan $40 \%$ o más cuando se transfieren dos o más embriones. Los resultados parecen ser mejores en las mujeres sin función ovárica que en aquellas con ciclos mensuales, quizá porque presentan un endometrio en reposo que reacciona mejor a la estimulación hormonal exógena.

No existen diferencias significativas en las tasas de embarazos de receptoras menores de 40 años y las mayores de esa edad. Los mayores riesgos son prematuridad del recién nacido y retardo del crecimiento intrauterino, especialmente en hijos de madres con hipertensión arterial. Sin embargo, los estudios indican que con un buen control de embarazo y manejo del parto, las mayores de 40 años no experimentan deterioro de la salud y la mortalidad perinatal puede alcanzar niveles similares a la de hijos de mujeres menores de 40 años.

Pasados los 50 años, todos los embarazos pueden considerarse de alto riesgo, pues se asocian con un importante porcentaje de complicaciones. En un grupo de 34 mujeres mayores de 50 años se lograron 18 embarazos (53\%) incluidos uno doble y uno triple. Solo hubo un aborto, 12 pacientes dieron a luz y cinco continuaban embarazadas en el momento del informe. Dos sufrieron diabetes gestacional, dos preeclampsia moderada y tres preeclampsia grave. Los recién nacidos pesaron de 900 a $3500 \mathrm{~g}$, con un promedio de $2430 \mathrm{~g}$. La edad de la gestación en el parto fue entre 31 y 39 semanas, con un promedio de 35,5 . No hubo mortalidad materna ni fetal y todas las mujeres recuperaron su estado de salud previo al embarazo.

Para prevenir complicaciones, en todas las mayores de 40 años que deseen embarazo debe practicarse electrocardiograma de esfuerzo, radiografía de tórax y de mamas, prueba de tolerancia a la glucosa, insulinemia, pruebas hepáticas, perfil bioquímico y lipídico, tiempo de protrombina y TTPK, VHS y hemograma, y estudios citológicos de frotis cervical. Es prudente tratar el embarazo y el parto con criterio de alto riesgo. Actualmente el promedio 
de vida de la mujer excede de los 70 años y si las condiciones de salud, psicológicas y sociales de la posible receptora y su cónyuge son satisfactorias, la donación de ovocitos no debe ser excluida solo por la edad. (Cheviakoff S. La donación de ovocitos como terapia en infertilidad. Rev Chil Obstet Ginecol 1996;61(4):276-280.)

\section{La compleja función de los opioides naturales del organismo}

Desde los años setenta se sabe que el cuerpo tiene un sistema natural de opioides que produce efectos similares a los de opiáceos como la heroína y la morfina. El organismo no solo cuenta con receptores "mu" que responden a los opiáceos, sino que también produce opioides y los libera durante el ejercicio y situaciones de estrés o dolor. Ahora se ha descubierto que además de ser esencial en la respuesta al dolor y a la euforia causada por ciertas drogas, el receptor mu en la membrana celular parece tener efectos mucho más amplios e importantes de lo que se pensaba.

El mismo grupo de investigadores de la Universidad de Indiana que descifró originalmente el código genético del receptor mu acaba de descubrir que, en murinos, el fallo del gen que habilita a ese receptor no solo elimina la respuesta a las drogas mencionadas, sino que reduce las funciones sexuales y reproductivas y altera el sistema inmunitario. En murinos sin receptores mu aumentó la producción de células progenitoras, incluso de leucocitos, en la médula ósea y el bazo. En los machos disminuyó la actividad sexual y producción de espermatozoos y las camadas que engendraron fueron más pequeñas. Esos efectos tienen un paralelo en el decaimiento del impulso sexual y en la reducción de la función inmunitaria que ocurren en humanos adictos a la heroína y la morfina.

La conclusión es que los opiáceos, además de afectar al temperamento y causar adicción, producen cambios en la capacidad reproductiva y en la resistencia a las infecciones y otras enfermedades. Esta nueva información hace destacar las amplias repercusiones del uso de narcóticos en la salud individual y pública. Se espera que la mejor comprensión de la estructura y funciones del receptor ayude en gran medida en la preparación de medicamentos nuevos contra el uso de los opiáceos y la adicción a ellos y sus consecuencias. (National Institutes of Health (NIH), National Institute on Drug Abuse. Role found for natural body opioids in reproduction and resistance to infection. Comunicado de prensa del martes, 22 de abril de 1997.)

\section{Restricción legal de la venta y distribución de productos de tabaco en los Estados Unidos}

La Administración de Alimentos y Medicamentos (FDA) de los Estados Unidos ha emitido regulaciones que restringen el acceso de niños y adolescentes a cigarrillos y tabaco sin humo que contienen nicotina y a la promoción de esos productos. Las regulaciones prohíben la venta de dichos cigarrillos y tabaco sin humo a individuos menores de 18 años $\mathrm{y}$ requieren que los fabricantes, distribuidores y vendedores cumplan con las siguientes condiciones: verificar la edad de los compradores mediante tarjetas de identificación que tengan fotos; prohibir la distribución de muestras gratuitas y la venta en máquinas y otras formas de autoservicio, excepto en lugares donde no estén presentes ni se permita jamás la entrada de menores de 18 años; limitar los anuncios y etiquetas que puedan ver los niños y adolescentes a texto escrito solamente en blanco y negro; prohibir la venta o distribución de productos no tabáquicos, como camisetas y gorras, que se identifiquen con alguna marca comercial de productos tabáquicos; prohibir el uso del nombre de cualquier marca comercial de productos tabáquicos como patrocinador de eventos o equipos deportivos, pero permitir el uso del nombre de la corporación; y exigir que los fabricantes incluyan información sobre el uso a que se destina el producto en todas las etiquetas de paquetes de cigarrillos y tabaco sin humo y en la propaganda comercial.

Estas regulaciones abordan los graves problemas de salud pública causados por los cigarrillos y el tabaco sin humo. Limitarán el fácil acceso de niños y adolescentes menores de 18 años a esos productos y reducirán notablemente las persuasivas imágenes propagandísticas que suelen atraer a ese grupo de edad. (United States of America. Regulations restricting the sale and distribution of cigarettes and smokeless tobacco to protect children and adolescents; final rule. Int Dig Health Legis 1997; 47:489-490.) 